high-performance material to remove fluoride from groundwater in the Ethiopian Riff Valley. "Technologies used in developed nations, like reverse osmosis, activated alumina beds, and synthetic resins are expensive technologies and require high maintenance," Muhoro explains. The researchers have made beds of layered aluminum oxide material infused with calcium that can reduce fluoride levels and completely remove phosphates, sulfates, and nitrates from groundwater.

The ambitious three-year CLEAN Project that started in 2014, meanwhile, is a partnership between scientists at the Universitas Gadjah Mada in Indonesia and Cornell University, who aim to convert a large land fill site near Jakarta, Indonesia, into an environmentally friendly renewable energy plant. The site handles 50006000 tons of municipal solid waste per day, with leachate volume reaching 100-1000 $\mathrm{m}^{3}$. If treated appropriately, the waste and leachate could potentially produce enough biogas to generate 200 megawatthours of electricity every day.

The deadline for this year's cycle of PEER projects passed in January 2016. The next call for proposals is expected to be announced on the PEER website near October 1.

Prachi Patel

\section{Report finds underrepresentation of women in world science} www.assaf.org.za

$\mathrm{D}$ espite efforts to promote the role of women in science, a recent study reveals little representation and participation of women in national science academies globally.

The first comprehensive survey of member academies of the Inter Academy Partnership (IAP): The Global Network of Science Academies finds that the average share of women members across 69 national science academies is $12 \%$. In just under one-half, 30 academies of the 69 that responded, the share of women members was either $10 \%$ or less.

The report Women for Science: Inclusion and Participation in Academies of Science was supported by the IAP and published by the Academy of Science of South Africa (ASSAf). It documents the results of two surveys undertaken by the Inter-American Network of Academies of Sciences (IANAS) and ASSAf, targeting member countries of the IAP. Other partners were the Organization for Women in Science for the Developing World (OWSD) and the Network of African Science Academies (NASAC).

The report points out that while "great strides have been made in enrolling more women in undergraduate courses, especially in the biological and chemical sciences (success has been more limited in the areas of physics, mathematics and engineering), there remain significant challenges in ensuring that women scientists are able to have fulfilling careers with increasing levels of responsibility, eventually taking up leadership and decision-making positions."

Women are "best" represented in the social sciences, humanities, and arts $(16 \%$ of all members in this discipline, across all science academies, are women), followed by the biological sciences $(15 \%)$, and the medical and health sciences (14\%). Women's representation as academy members is least in the mathematical sciences $(6 \%)$ and engineering sciences $(5 \%)$.

Findings for the three global science academies-Islamic World Academy of Sciences (IAS), the World Academy of Art \& Science (WAAS), and The World Academy of Sciences (TWAS) — show a similar picture: women are "best" represented among academy members in the social sciences and humanities.
EU seeks views regarding its transition to a sustainable economy http://ec.europa.eu/research/consultations/euric/consultation_en.htm

$\mathrm{T}^{\mathrm{h}}$ he European Commission has launched a public consultation on the development of an Integrated Research, Innovation, and Competitiveness Strategy aimed at facilitating the European Union's (EU) transition to a sustainable, competitive, energy-efficient, and low-carbon economy.

The strategy is linked to the implementation of the Energy Union Communication, which called for more research and innovation to ensure that the energy transition happens through modern, user-friendly, safe, sustainable, and secure solutions to the benefit of EU citizens and businesses. Commitments taken at the COP21 International Climate Conference in Paris in December 2015 reinforce the need to step up efforts for reaching agreed climate targets.

The Commission is inviting all stakeholders and interested parties, including EU citizens, and private and public organizations to share their views on how to achieve the EU's energy and climate targets, as well as sector-specific research, development, and innovation goals needed for the transformation. The consultation will also look into the competitiveness of EU economic factors and new business opportunities, and examine how transport - one of the main energy users in the EU — can contribute to achieving the overall climate and energy goals.

The consultation will run through May 31, 2016, and its findings will feed into the integrated Research, Innovation, and Competitiveness strategy to be presented at the end of 2016. 